\title{
APERCEPCIÓN DE VALOR Y TONALIDAD AFECTIVA: PROBLEMAS DE LA FENOMENOLOGÍA HUSSERLIANA DE LOS SENTIMIENTOS
}

\section{Value Apperception and Affective Tonality: Problems of Husserlian Phenomenology of Feelings}

\begin{abstract}
Resumen: De acuerdo con la fenomenología husserliana la experiencia primordial del valor descansa en vivencias emotivas. Para sostener esta idea Husserl sugiere el paralelismo entre la percepción externa y la percepción de los valores. El objetivo de este trabajo es clarificar tal paralelismo enfatizando un problema particular del análisis husserliano: la tonalidad afectiva del objeto de valor y su relación con la apercepción sentimental involucrada en la experiencia de los valores.
\end{abstract}

Palabras clave: Apercepción de valor | Temple de ánimo | Fenomenología | Sentimientos
Ignacio Quepons

Seattle University, Estados Unidos iquepons@gmail.com

\begin{abstract}
According to husserlian phenomenology the primordial experience of value lays in emotive lived-experiences. In order to sustain his Idea Husserl suggest a parallelism between the external perception and the perception of values. The aim of this work is to clarify such parallelism stressing a particular problem of husserlian analysis: the affective tonality of the object of value and its relation to the feeling apperception involved in the experience of values.
\end{abstract}

Key Words: Value apperception | Mood | Phenomenology | Feelings

\section{INTRODUCCIÓN}

El objetivo de este ensayo es presentar algunos contextos del problema de los sentimientos sensibles [Gefüh/sempfindungen] y su unidad con los actos de sentimiento como acceso a la esfera del valor en la fenomenología de Husserl. Una de las características más importantes del planteamiento axiológico de Husserl es que el fundamento del juicio de valor descansa en experiencias del sentimiento. Los valores, lejos de ser el resultado de un mero consenso lingüís- 
tico o de la argumentación conceptual, son captados originariamente como resultado de una apercepción emotiva de su sentido ${ }^{1}$.

Lo controvertido de la posición de Husserl es precisamente la difícil determinación de las características de la apercepción emotiva del valor, y el lugar de los sentimientos sensibles en su exhibición. En particular, es importante destacar cómo la apercepción afectiva tiene como correlato objetivo una cualidad apercibida como la exhibición cuasi-sensible del valor en el objeto. Husserl llama a dicho correlato "coloración emotiva", "luz" o "resplandor", el cual es a su vez captado en referencia a una "corriente del sentimiento" coherente con el volverse emotivo hacia el objeto que se descubre con cierto valor.

La aclaración del lugar de la exhibición sensible de los valores es decisiva en la descripción de la "apercepción del valor" en el objeto que da lugar al "volverse emotivo" y que forma parte de la fundamentación fenomenológica del juicio axiológico ${ }^{2}$. Este problema aparece en el parágrafo $\S 15$ de la Quinta de las Investigaciones Lógicas, y en diferentes manuscritos de investigación de entre 1909 y 1911 , pertenecientes al periodo de transición hacia sus Ideas I, y es coherente con el desarrollo de su teoría del valor en sus lecciones de ética.

En las siguientes páginas trataremos de ordenar los contextos de la aclaración de esta temática dentro de una descripción integral de la vida afectiva y su relación con la experiencia del valor. En el primer apartado analizaremos la diferencia entre sentimientos como actos intencionales y como sentimientos sensibles [Gefüh/sempfindungen]. Como veremos en nuestro análisis, el paralelismo entre la apercepción empírica y la apercepción de valor que quiere sugerir Husserl, en virtud del comportamiento mismo de los sentimientos sensibles, no es estricto. Sin embargo, esto no hace menos plausible su planteamiento, aunque sí cabe hacer algunas precisiones, como la aclaración del papel del cuerpo vivo [Leib] en la manifestación sensible de los valores a través de nuestra vida afectiva.

En el segundo apartado, avanzaremos a la exposición de la función exhibidora de los sentimientos sensibles en la apercepción afectiva del valor, como aparece en los manuscritos de investigación ${ }^{3}$ del periodo de transición entre

\footnotetext{
${ }^{1}$ Hua III/1, 75

${ }^{2}$ Hua XXVIII, 60. Sobre este tema véase Ferrer Santos (2012: 78-79)

${ }^{3} \mathrm{Me}$ refiero sobre todo a los manuscritos que fueron integrados en el proyecto inédito conocido como Estudios sobre la estructura de la conciencia, cuya transcripción y edición a cargo de Ludwig Landgrebe se encuentra en los Archivos Husserl clasificado con la nomenclatura M III 3, I-III; no obstante, a lo
} 
Investigaciones Lógicas e Ideas I. Nuestra contribución se cierra con algunas reflexiones en torno al tema de la "tonalidad" o coloración emotiva del entorno que aparece por igual en las Investigaciones Lógicas y algunos manuscritos de investigación, así como con una posible solución al problema de la determinación de su papel dentro de una descripción fenomenológica de la vida afectiva.

\section{Sentimientos SENSIBLES Y ACtOS DE SENTIMIENTO}

En Investigaciones Lógicas, Husserl plantea la cuestión de la vida afectiva en dos momentos: primero se pregunta si corresponden a la esfera de la vida afectiva ciertas especies de vivencias a las cuales les sea esencial una referencia intencional y, en segundo lugar, si esta referencia intencional puede faltar a otras vivencias de la misma esfera emotiva. Primero, analiza el carácter esencial de las vivencias del sentimiento entendidas como acto $y$, en el segundo, distingue entre los sentimientos sensibles, no intencionales ${ }^{4}$, y los sentimientos como actos ${ }^{5}$. Al hacerlo, Husserl aparentemente intenta trazar un paralelismo entre los contenidos de aprehensión de actos como la percepción y cierta aprehensión de vivencias del sentimiento entrelazadas con la sensibilidad, como el placer y el dolor, y la intencionalidad de actos como los del agrado o el desagrado. La aprehensión perceptiva, ella misma intencional, da el sentido de exhibición de cualidades de un objeto a la mera apercepción de momentos empíricos como formas y colores. De la misma forma, la intencionalidad del volverse con agrado hacia lo agradable aprehendería lo que Husserl, en sus manuscritos de investigación, llamará la "apercepción emotiva del valor" la cual está manifiesta en una coloración o tonalidad "de lo agradable" en el objeto.

largo de este estudio nos referiremos a la transcripción de los manuscritos originales que datan de entre 1909 y 1911 , y que sirvieron de base a la versión de Landgrebe.

${ }^{4}$ Hua XIX/1, 402.

${ }^{5}$ Es importante tener en cuenta aquí que Husserl, en Investigaciones Lógicas, no ha distinguido todavía entre vivencias intencionales que son actos de las que no lo son. Esta distinción aparece explícitamente en Ideas I, § 36 Hua III/1,74. La omisión de esta precisión en el concepto de "vivencia intencional" ha derivado en algunos malos entendidos en lo que se refiere a la fenomenología de los actos afectivos. Cfr. $\mathrm{Ni}$, Liangkang (2007: 67-82). Es importante considerar que los sentimientos como vivencias intencionales, en el sentido de actos, se dirigen directamente su objeto, pero hay otras formas de intencionalidad no temática que intervienen en la vida afectiva: los temples de ánimo. La ampliación de la noción de intencionalidad es lo que permitirá explorar el problema de la intencionalidad de fenómenos como la iluminación emotiva del entorno producida por la experiencia del agrado ante el objeto de un acto emotivo. Sobre una posibilidad de interpretar el temple de ánimo desde una perspectiva de los horizontes intencionales véase, Quepons, 2015. 
Antes de avanzar a esta cuestión, es preciso aclarar el sentido de la intencionalidad de los sentimientos. De acuerdo a la presentación de Husserl, algunos estudiosos del tema no consideran a los sentimientos como actos intencionales sino como meros estados psicológicos. La relación intencional manifiesta en vivencias como el amor y lo amado se debe, de acuerdo a esta apreciación, a una "complicación" entre representaciones. Frente a esta postura, Brentano defendía la intencionalidad del sentimiento, puesto que éste tiene por base representaciones, como todos los actos que no son meras representaciones. Para Brentano, habría dos representaciones edificadas una sobre la otra: "la fundadora", que proporciona el objeto representado, y la representación fundada, que proporciona el sentimiento sobre el objeto representado. Husserl toma partido a favor de Brentano, pero a su vez señala que "no tenemos meramente la representación y además el sentimiento, como algo exento en sí y por sí de referencia a la cosa, bien que enlazado con ella de un modo meramente asociativo, sino que el agrado o el desagrado se dirigen al objeto representado, y sin esta dirección no pueden existir" ${ }^{\prime \prime}$.

Para Husserl, el acto fundante, la representación base, es la materia del acto completo donde el sentimiento, como acto, cumple el papel de cualidad intencional. Dado que es un acto no-objetivante, es decir, no se "dota a sí mismo de su propio objeto", necesita de una representación como soporte de su dirección intencional; sin embargo, dicha representación base es la "materia" (sentido objetivo) de la esencia intencional que integra al acto afectivo como acto fundado. De acuerdo a la doctrina de las Investigaciones Lógicas, el sentido de un acto, su significación, es el resultado de considerar en su generalidad lo que aquí llama la "esencia intencional", la cual es la conjunción entre el sentido objetivo, el objeto mentado en cuanto tal, y el modo de la mención. Husserl llama al primer elemento "materia" y al segundo "cualidad"7. Un acto de reflexión dirigido a la explicitación de la materia de acto emotivo descubre al objeto en cuanto tal con relativa independencia de su determinación emotiva.

La modalidad afectiva en que el objeto es intencionado constituye un momento primordial de su sentido, y es desde este carácter afectivo que es intencionado. No obstante, la objetividad mentada en cuanto tal descansa en la re-

\footnotetext{
${ }^{6}$ Hua XIX/1, 403.

7 Hua XIX §§ 20-24.
} 
presentación que ofrece otro acto de carácter objetivante. En este género de actos, entran la percepción, el mentar judicativo de la esfera lógico-dóxica, la representación en la fantasía o la rememoración.

Un agrado sin algo agradable es inconcebible. Y no sólo porque nos encontremos aquí con expresiones correlativas, como, por ejemplo, cuando decimos que no es concebible una causa sin efecto o un padre sin hijo; sino porque la esencia específica del agrado exige la referencia a algo agradable ${ }^{8}$.

Tan absurdo resulta un acto de mención emotiva sin objeto mentado emotivamente, como es un contrasentido tomar en cuenta la relación intencional, aquí y en general, como una relación causal, o sea, darle el sentido de una conexión necesaria empírica y sustancial. El objeto intencional, que es apercibido como "causante", sólo entra en cuenta aquí como intencional, no como existiendo realmente fuera de mí y determinando real, psicofísicamente, mi vida psíquica. $^{9}$

El complacerse o el sentirse complacido no "pertenecen" a este paisaje como realidad física, ni como efecto físico, sino que pertenecen, en la conciencia actual aquí en cuestión, en cuanto aparece así o de este otro modo, eventualmente en cuanto es juzgado así o de otro modo, en cuanto recuerda aquello, etc.; como tal, "exige", "despierta" semejantes sentimientos ${ }^{10}$.

Por otro lado, tenemos que la noción de "sentimiento" se refiere también a vivencias o caracteres de vivencias no intencionales.

Cuando nos quemamos, no cabe poner ciertamente el dolor sensible en el mismo plano que una convicción, una presunción, una volición, etc.; sino en el mismo que contenidos de sensación como la aspereza o la suavidad, el rojo o el azul, etc. Si nos representamos semejantes dolores o cualesquiera placeres sensibles cualesquiera, como el aroma de una rosa, la dulzura de un manjar, etc. encontramos también que los sentimientos sensibles se hallan fundidos con las sensaciones pertenecientes a la esfera de este o aquel sentido, de un modo enteramente análogo a aquel en que se hallan estas sensaciones entre si $^{11}$.

Es interesante que Husserl se refiera en este contexto a los sentimientos sensibles como "fundidos" con las sensaciones pertenecientes a la esfera de

\footnotetext{
${ }^{8}$ Hua XIX/1, 405.

${ }^{9}$ Aunque, por otra parte, sí son objeto de investigación fenomenológica las síntesis asociativas y los vínculos de motivación que intervienen en el despertar de vivencias emotivas en la aprehensión de determinados objetos de la experiencia. No obstante, la delimitación husserliana es aquí pertinente toda vez que se trata de desplazar toda causalidad en sentido psicofísico-empírico.

${ }^{10}$ Hua XIX/1, 405.

${ }^{11}$ Hua XIX/1, 406.
} 
algún sentido. En su ejemplo de la quemadura, que se realiza en el sentido del tacto, la sensación de toque revela una determinación sensible del objeto tocado y el cuerpo mismo se apercibe a sí mismo, de manera localizada, en la captación táctil ${ }^{12}$. Con el dolor de la quemadura, tenemos el dolor como sensación localizada y la determinación del objeto caliente. Pero el cuerpo no "arde" (en el sentido en que decimos que un "fuego" arde), sino que "duele" por efecto de la excesiva intensidad de calor que sentimos en el objeto ${ }^{13}$.

Todo sentimiento sensible, por ejemplo, el dolor de quemarse, está referido en cierto sentido a objetos; por una parte al yo, o más concretamente al miembro corporal quemado; por otra parte al objeto ardiente ${ }^{14}$.

Esta relación sólo se da en las sensaciones táctiles, es una característica de su naturaleza, el cuerpo se apercibe a sí mismo sintiendo táctilmente otros objetos, aunque también hay una cierta referencia al cuerpo en los sentimientos sensibles referidos a los sentidos corporales como el olfato o el oído, pero no de manera tan explícita como sucede con las sensaciones táctiles. Lo cierto es que, en cualquier caso, los sentimientos sensibles no son vivencias intencionales.

Las sensaciones funcionan aquí como contenidos representantes de actos de percepción, o como se dice de un modo no enteramente inequívoco, las sensaciones experimentan aquí una «aprehensión» objetiva. Ellas mismas no son, pues actos; pero con ellos se constituyen actos cuando se apoderan de ellas, prestándoles vida, por decirlo así, caracteres intencionales de la índole de la aprehensión perceptiva ${ }^{15}$.

Las sensaciones que se dan en contextos concretos integradas en aprehensiones intuitivas de algún tipo pueden ser ellas mismas objetos de aprehensión y en ese sentido no cumplir su función exhibidora, pese a que difícilmente se podrían pensar sin alguna referencia tácita a exhibir un "algo" por indeterminado que sea (una superficie, una textura táctil, etc.). Los sentimientos sensibles, por otra parte, comparten con las sensaciones este carácter no intencional. No obstante ¿son sus contenidos representantes al modo en que lo es la sensación de color, por ejemplo, respecto de la percepción? Husserl sugiere que, en el

\footnotetext{
12 Véase $\S 36$ de Ideas II.

${ }^{13}$ La expresión es ambigua pues utilizamos en el lenguaje cotidiano "me arde" cuando nos referimos a la irritación cutánea dolorosa que resulta de una quemadura. En todo caso me refiero a que el "ardor", en el sentido de irritación dolorosa, es diferente en su significado de la palabra "ardor" en el sentido de intensidad térmica. Cuando decimos "la flama ardiente" o "que arde" evidentemente nos referimos a su intensidad térmica y no a la sensación. Acaso el énfasis está en el reflexivo "me" donde se marca la diferencia.

${ }^{14}$ Hua XIX/1, 406.

15 Hua XIX/1, 406.
} 
mejor de los casos, son contenidos representantes u objetos de intenciones referidas a ellos, no intenciones en sí mismas. Esto quiere decir que son contenidos que exhiben intuitivamente el objeto de una aprehensión o que pueden ser ellos mismos objetos de otros actos de aprehensión dirigidos a ellos (rasgo compartido con las sensaciones), como cuando ponemos atención al color rojo de una manzana, pero atendiendo únicamente al color y no a la manzana que se exhibe intuitivamente en su coloración roja ${ }^{16}$.

La diferencia entre sentimientos sensibles y las "meras sensaciones", sobre todo las sensaciones ya "aprehendidas" como contenidos representantes de objetos de la percepción, como el color o las texturas, es que un momento de la sensación puede ser aprehendida como contenido representante del objeto. $Y$ en otro momento ocurrido simultáneamente, la sensación es aprehendida como sentimiento sensible. Cuando tocamos la superficie de un durazno, no sólo constatamos sensiblemente su textura, y esa sensación suave no es sólo un contenido expositivo del durazno para la percepción sensible-táctil, sino que además la sensación como tal nos resulta agradable al contacto. Aprehendemos la suavidad misma como placentera y dotamos a esa misma suavidad de una tonalidad afectiva. Podemos pensar "qué suave se siente este durazno", no en el sentido de constatar una caracterización objetiva del mismo, sino porque vemos o aprehendemos en esa suavidad una cualidad placentera ${ }^{17}$.

Un poco más adelante, en el mismo parágrafo 15 de la Quinta de las Investigaciones Lógicas, Husserl reflexiona sobre la posibilidad de incluir como parte del mismo género los sentimientos como actos y los sentimientos sensibles. En cierto sentido, estos sentimientos sensibles o, mejor dicho, sensaciones afectivas, son la base para la aprehensión del contenido representante del objeto del acto intencional y no el acto como tal, por lo cual son aprehendidos por la intencionalidad de los actos de sentimiento y en esta medida exhiben, de acuerdo

\footnotetext{
${ }^{16}$ Además de que en el caso del rojo de la manzana como objeto de una aprehensión dirigida a éste, cabe distinguir entre la aprehensión de ese rojo exhibiéndose intuitivamente en cuanto tal, con su matiz intuitivo dado, y otras aprehensiones dirigidas al "rojo en general", del cual el rojo de la manzana, captado analíticamente y en esa medida desembarazado de su función exhibidora (al menos de su función exhibidora de manzana porque exhibe una superficie coloreada, pero el tema de nuestra atención es el tono de color y no la superficie), es una instancia de dicho rojo en general.

${ }_{17}$ A esto habría que agregar que la constatación sensible del objeto es simultáneamente apercepción de nuestro propio cuerpo sensible, en lo que Husserl llama "ubiestesias". Al tocar el objeto nos sentimos a nosotros mismos como cuerpo. Véase, Hua IV, 146.
} 
a determinaciones sensibles de sentimiento, el objeto de la representación del acto afectivo ${ }^{18}$.

Husserl ejemplifica esta situación con un esbozo de la descripción de la alegría y la tristeza:

la alegría por un evento feliz es seguramente un acto. Pero este acto, que no es un mero carácter intencional, sino una vivencia concreta y eo ipso compleja, no sólo comprende en su unidad la representación del suceso alegre y el carácter de acto del agrado referido a éste, sino que la representación se enlaza con una sensación de placer, que es apercibida y localizada como excitación afectiva del sujeto psicofísico sensible y como propiedad objetiva; el suceso aparece como recubierto por un resplandor ${ }^{19}$ rosado. El suceso matizado de placer por este modo es como tal el fundamento de volverse alegremente hacia el objeto del agrado, complacerse 0 como quiera que se llame. Igualmente, un suceso triste no es meramente representado en su contenido y conexión objetivos, en lo que implica en sí y por sí como suceso, sino que aparece como revestido del color de la tristeza. Las mismas sensaciones de desplacer que el yo empírico refiere a sí y localiza en sí (como dolor en el corazón) son referidas, en la apercepción afectiva del suceso, a este mismo ${ }^{20}$.

Las mismas sensaciones afectivas que el yo refiere a sí y localiza en sí son referidas en la percepción afectiva del suceso al suceso mismo. Se trata de referencias que son puramente representativas, es decir, no se refieren a determinaciones objetivas del suceso, sino que son, dice Husserl aquí, "puramente representativas" $^{21}$. En este sentido estas sensaciones son la base para su aprehensión como contenidos exhibidores del objeto mentado afectivamente. Un rasgo interesante de las sensaciones localizadas que son "referidas en la apercepción afectiva del suceso" es que de hecho son captadas como tales an-

18 ¿Es posible la vivencia del sentimiento como mera mención sin los sentimientos sensibles en un caso semejante al de la significación y la base sensible de la expresión? La aprehensión del sentido objetivo del nóema del acto afectivo no requiere de los contenidos expositivos que en este caso serían los sentimientos sensibles, pero en cualquier caso los sentimientos sensibles dan plenitud intuitiva a la mención afectiva.

19 "das Ereignis escheint als wie von einen rosigen Schimmer umflossen", José Gaos traduce "Schimmer" como "velo", en este caso, "velo rosado". Modificamos la traducción de acuerdo a Antonio Zirión (2009: 145).

${ }^{20}$ Hua XIX/1, 408.

${ }^{21}$ Husserl así lo afirma, pero el hecho de que sean "las mismas sensaciones afectivas" en uno y otro caso no resulta nada claro. En realidad, Husserl está extendiendo el paralelismo con base en otros contenidos sensibles de la percepción como el color, por ejemplo. Si tomamos en cuenta sensaciones localizadas del tipo del dolor de la quemadura, difícilmente podemos atribuir la sensación "afectiva" de la quemadura al objeto que "quema". En el mismo ejemplo de Husserl, que es todavía más difícil de describir, ¿qué significa la atribución de la misma sensación de "placer" al objeto como una cualidad representativa? Nótese que Husserl dice además "localiza en sí". Si es dudoso que la emoción de la alegría se identifique con la sensación concomitante que ocurre en el estómago cuando nos alegramos, o la opresión en el pecho de la tristeza, ¿cómo podría atribuirse "la misma sensación afectiva" que el sujeto "refiere y localiza en sí" al suceso mismo? Así sea de forma meramente representativa, la forma específica en que ocurre esa representación -que el objeto esté "bañado por la luz de la alegría", sea lo que eso signifique- resulta bastante difícil de describir. Volveremos sobre el tema del "resplandor" afectivo del objeto más adelante. 
tes del volverme con alegría hacia el suceso feliz. En cierto modo la amenidad o alegría del suceso "alegre" brilla o se exhibe a través de lo que Husserl llama en este ejemplo el "resplandor rosado". El suceso es ya representado como feliz y sobra la base de esta apercepción afectiva, o como la llamará después, valorativa, me vuelvo con alegría al mismo.

Aquí hay que señalar, no obstante, un problema importante que constituye un rasgo distintivo entre los sentimientos sensibles y las meras sensaciones. Husserl admite que dichos sentimientos sensibles pueden durar o mantenerse después de que el objeto de la suscitación afectiva ya no esté presente.

Cuando los hechos suscitadores del placer han pasado a segundo término, cuando ya no son coloreados afectivamente e incluso quizá ya no son objetos intencionales, la excitación placentera puede durar todavía largo tiempo y eventualmente es sentida como agradable; en lugar de funcionar como representante de una propiedad agradable del objeto, es referida meramente al sujeto sensible o es ella misma un objeto representado y agradable 22 .

En primer lugar, los sentimientos sensibles o sensaciones afectivas pueden o no estar dirigidos a objetos; aquí se problematiza en parte su consideración como contenidos representativos del objeto de un acto aprehensor, pues pueden o no estar exhibiendo algo en específico. En su referencia a objetos, estas sensaciones están referidas al revestimiento o del resplandor o iluminación afectiva.

Ahora bien, las sensaciones afectivas, señala Husserl, pueden además durar sin que el objeto que las suscitó siga presente. ¿Cómo tendríamos que explicar esto? Primero, habría que decir que no se afirma sólo que el objeto no esté dado ya perceptivamente, lo que admitiría otros modos de dación como el recuerdo o la conciencia de imagen; sino que el objeto no está dado en ningún sentido, ni siquiera en modo re-presentativo. Si fuera ese el caso, las sensaciones afectivas seguirían guardando esta referencia objetiva $y$, en ese sentido, seguirían siendo contenidos exhibidores del objeto, así sea en modo puramente representativo [vorstellungsmässige] ${ }^{23}$. La ausencia del objeto es ausencia en

\footnotetext{
22 Hua XIX/1, 409.

${ }^{23}$ El recurso de Husserl a esta expresión para referirse a la forma en la que aparece el resplandor en el objeto puede sugerir, y así lo interpretamos aquí, que es meramente subjetivo, es decir, corresponde a la forma en la que el sujeto se lo representa. Pero un rasgo importante aquí, y quizá esta sea la importancia del adjetivo, es que el resplandor es la forma en la que el objeto se presenta, es decir, no depende de la manera "subjetiva" en la que podemos representárnoslo, de acuerdo a nuestra opinión o gusto y gana, por así decir. Con subjetivo queremos decir que el objeto comparece "iluminado" para el sujeto conmovido por su presencia, que capta su valiosidad de forma "sensible" por así decir y es por efecto de
} 
cualquier sentido de representación: el sujeto conserva las sensaciones afectivas sin el polo objetivo o "resplandor" en el objeto ${ }^{24}$.

Ésta es una diferencia fundamental con las meras sensaciones como el color, el cual exige esta referencia objetiva casi como condición de posibilidad (incluso en aquellos casos en que es objeto de aprehensión y no contenido expositivo de un objeto aprehendido), aunque el objeto del cual es representante intuitivo no esté necesariamente bien determinado. Las sensaciones afectivas se mantienen y pueden ser captadas ellas mismas sin la referencia objetiva presente, cosa que no sucede nunca con el $\operatorname{color}^{25}$.

esta apercepción afectiva que después nos volvemos con alegría al objeto. Antonio Zirión suscribe una interpretación semejante en su artículo "El resplandor de la afectividad" (2009). En una comunicación personal reciente me ha señalado, no obstante, que ahora encuentra su interpretación problemática, precisamente por el concepto de "vorstellungsmässige" remite, según su nueva apreciación, a la presentación del concepto de Vorstellung a lo largo de la Quinta Investigación Lógica. Esto sugiere que el resplandor no es del acto de agrado sino de la representación, pertenece por tanto al orden del acto objetivante de las representaciones. A reserva de una discusión más amplia del particular, debemos señalar que la apercepción del valor no depende de la exhibición "empírica", en este caso, del suceso feliz y su carácter "ameno" sólo lo es para quienes se conmueven ante su presencia, quienes ven o "sienten" su valor en esa presencia. Sólo ante ellos el suceso comparece revestido por un resplandor rosado, para las demás personas el suceso mismo puede resultar incluso indiferente, y en consecuencia, incluso cuando lo perciben también, no comparece ante ellos bañado de ningún resplandor. En efecto, el resplandor tiene una anterioridad respecto del volverse con agrado, y esa anterioridad corresponde de hecho con la apercepción sensible del valor en el objeto, el cual "resplandece" precisamente por su valor, y por esa razón nos volvemos a él con agrado o alegría. La manera precisa en que tengamos que entender la idea de "puramente representativo" aquí merece mucha discusión, y tiene razón Zirión en señalar la anterioridad del resplandor respecto del volverse de la alegría; no obstante, el resplandor es afectivo y en sentido estricto fundado en la representación del suceso, por tanto no es "meramente representativo" en sentido derivado de Vorstellung, como la representación objetiva del suceso. Por el contrario, la expresión "meramente representativo" se referiría más bien a que es algo subjetivo en el sentido de que "no es nada" en el objeto sino la forma en la cual sujeto que capta el objeto como valioso se lo representa debido a su valor. El adjetivo meramente representativo señala que el resplandor no es una propiedad "real" del objeto. No obstante, vale la pena recordar que el resultado no es una un correlato puesto encima del otro sino una sola representación fundada: la del suceso feliz que aparece justamente así, resplandeciente, para quien se vuelve con alegría por su valor.

${ }^{24}$ Esto no quiere decir que ese tono afectivo que mantiene el sujeto no tenga ningún correlato noemático. La "iluminación" afectiva puede pasar del objeto al entorno de la percepción, como cuando hablamos del tono de una tarde; no estamos vueltos ella, no obstante, permea emotivamente los objetos y estados de cosas que vivimos a su luz. Habrá que meditar qué paralelismo tiene esta "luz afectiva" con las modificaciones de la normalidad en la percepción de las que habla en Ideas II, particularmente en el §18. En este parágrafo aparece, además, una referencia a las modificaciones del ánimo y su influencia sobre el cuerpo. Lo interesante es que esta referencia se hace en el contexto del cuerpo como órgano de la percepción sensible, dice Husserl: "depende del cuerpo Y DE LO PROPIO DE LA PSIQUE QUE tiene frente a sí EL SUJETO COMO MUNDO. Incluso prescindiendo de los elementos reproductivos que intervienen en la apercepción de cosas, lo psíquico adquiere significación para la dación del mundo externo merced a las relaciones de dependencia que existen entre lo corporal y lo psíquico. El uso de estimulantes, las afecciones corpóreas, tienen como efecto la presentación de sensaciones, sentimientos sensibles, tendencias, etcétera. A la inversa, un estado anímico como la hilaridad, la melancolía y semejantes, ejerce influencia sobre los procesos corporales. Y gracias a estos nexos, el MUNDO EXTERNO APARETENTE se muestra como RELATIVO no meramente al CUERPO, sino al SUJETO PSICOFÍSICO EN SU TOTALIDAD" (Hua IV, 75). Dicho mundo aparente, entonces, gracias al nexo del correlato objetivo que aquí hemos llamado resplandor o "iluminación afectiva" y que aparece en ocasión a una modificación del ánimo o a una intencionalidad dirigida a un objeto afectivo que ya no está presente, contendría en principio el componente afectivo relativo a la influencia ejercida por la variación del temple de ánimo en el cuerpo y la psique del sujeto.

${ }^{25}$ En el caso de las sensaciones como el color, cuando es objeto de aprehensión, hay una mención implícita a cierto soporte exhibido (una superficie bidimensional), al menos en la forma de su mera representación, la cual se encuentra presente aunque no es tema de la atención. En el caso de las sensa- 
El ejemplo de Husserl presenta simultáneamente diferentes problemas que es necesario distinguir punto por punto. Si hay sensaciones afectivas que pueden durar sin que el objeto que las suscitó esté presente más, entonces no necesariamente están fundidas con sensaciones como en el ejemplo de la suavidad táctil o el dolor de la quemadura.

La sensación de la tristeza, comprendida de esta forma, esto es, como durando en el sujeto con independencia de la objetividad que la "suscitó", no se localiza en el cuerpo, al menos no al modo de los sentimientos sensibles fundidos en sensaciones localizadas corporalmente. El "dolor en el corazón" es una metáfora cuyo sentido se funda en el hecho de que cuando "sentimos tristeza" a veces también sentimos un malestar en el pecho, pero no identificamos sin más la sensación de tristeza con ese dolor, más bien decimos que cuando me siento triste me duele el pecho. ${ }^{26}$ Se trata de dos vivencias implicadas pero no unidas al modo de identificar el dolor en el pecho con la exhibición sensible de la tristeza; la tristeza se exhibe sensiblemente como un malestar de toda mi subjetividad concreta y no sólo en el pecho. ${ }^{27} \mathrm{O}$ bien, si tomamos el caso de la alegría, ¿dónde está la alegría como sensaciones alegres o alegrantes en la aprehensión de un suceso feliz? ¿Dónde está la suscitación sensible de la alegría? Sin duda existen estas sensaciones afectivas que no pueden ser ubicadas en el cuerpo (en el modo de su localización); más bien se trata de una cualidad afectiva, sensible, que determina la vida y que no se agota en las sensaciones localizadas implicadas en la vivencia afectiva completa de la alegría, y sobre todo, no se explican por esas sensaciones localizadas ${ }^{28}$.

ciones afectivas tenemos que su referencia implícita a la objetividad que las suscitó no requiere de la presencia o re-presentación del objeto suscitador. En un caso, hay una variación de la atención respecto de una objetividad presente $y$, en el otro, la referencia implícita a una objetividad ausente. Puede ser que el sujeto ni siquiera recuerde en ese momento por qué se siente así. Véase para esto último el comentario de Liangkang $\mathrm{Ni}$ a éste fragmento del parágrafo 15 de la Quinta de las Investigaciones Lógicas, en Liankang $\mathrm{Ni}$ (2007: 73-76).

${ }^{26}$ Véase por ejemplo el siguiente pasaje: "percibo que la angustia me oprime la garganta, que el dolor me taladra el diente, que la pena me roe el corazón, exactamente en el mismo sentido en que percibo que el viento sacude los árboles, que esta caja es cuadrada y de color pardo, etc." (Hua XIX/2, 761).

${ }^{27}$ Por ejemplo, diría Borges "me duele una mujer en todo el cuerpo". Justo el sentido poético de la imagen de Borges abraza el sentido de la magnitud de un dolor que abarca toda mi realidad y no es en modo alguno determinable en términos de localización corporal. Sin embargo, todo sentimiento y en este caso, todo sufrimiento vivo involucra en un sentido, todavía por aclarar, mi propio cuerpo vivo. La apercepción del sentimiento en la medida en que es una apercepción sensible es inconcebible sin la referencia a la experiencia corporal. Esto no quiere decir que su relación sea en el sentido de la "extensión" sino en el sentido de la vivencia de cuerpo (Leib) que funda la localización, y con ella, la extensión misma. Cfr. Hua XIII, 67.

${ }^{28}$ No obstante, tomando en cuenta el parágrafo 36 de Ideas II, al que nos hemos referido antes, eso no quiere decir que no tenga relación alguna o efecto sobre el cuerpo. Los sentimientos nos afectan corpo- 
Los sentimientos de sensación del tipo del placer y el dolor sensible están necesariamente fundidos con meras sensaciones que exhiben el objeto de la representación base. Sin embargo, los caracteres cuasi-objetivos del tipo del "resplandor" o la "coloración afectiva" guardan una relación paradojal con los contenidos sensibles de la apercepción del entorno, pues, a pesar de la manera como Husserl se refiere a ellos, casi siempre en términos de metáforas visuales, lo cierto es que no está clara en modo alguno la relación entre dichos caracteres y los "sentimientos sensibles que el sujeto vive y localiza en sí". Incluso en el caso del resplandor afectivo producido por la presencia de un objeto que agrada, por el placer sensible que provoca, la aprehensión del placer sensible como manifestación del agrado no guarda la misma relación que guarda el agrado con la "coloración afectiva" que exhibe al objeto representado como "ameno". Una mera mención vacía, por ejemplo, la enunciación del nombre de la amada, puede motivar el sentimiento de bienestar y eventualmente provocar el respectivo "resplandor" sobre el entorno sin la presencia de los sentimientos sensibles aprehendidos generalmente en la presencia viva de la amada.

Es así que se vuelve necesario distinguir entre los propios sentimientos sensibles, aquellos que se encuentran fundidos con sensaciones y que son captados por los sentidos en referencia a una localización corporal, y otro tipo de sentimientos sensibles que son la base para la aprehensión del objeto "representado emotivamente" por parte de las vivencias intencionales del sentimiento en la forma de determinaciones cualitativas sujetas a variación de intensidad y que darían pauta a la determinación precisa de lo que Husserl llama "resplandor de lo alegre". Este "resplandor", es, sin duda, un tipo de sentimiento sensible alejado de las sensaciones y de la ubicación corporal específica; además, estaría fundado por la determinación cualitativa de corte emotivo propia de la vivencia intencional en cada caso - la coloración es de tristeza o de alegría-, de modo que las vivencias de alegría en la mención de sus objetos se vuelven a ellos así porque estos estos comparezcan con el brillo de lo ameno ${ }^{29}$.

ralmente, lo único que se está precisando aquí es que su modo de manifestación sensible no se explica necesariamente a partir de su fundición con sensaciones localizadas. Véase Hua IV, 12 ss.

${ }^{29}$ Por otro lado, dicho bienestar sensible puede estar fundado en una vivencia intencional de alegría que no sea acto; por ejemplo, en el caso de que el objeto que suscitó la alegría ya no está presente y nuestra atención está dirigida a otro campo temático, pero mantenemos una referencia de fondo al objeto que "nos alegró la tarde", por decirlo así. Dicho de otro modo, el estado afectivo no es él mismo nointencional, pues puede implicar referencias intencionales no temáticas que conforman un fondo o contexto de vivencias que incluso pueden corresponder al ámbito no afectivo. Es posible que existan referencias latentes, de horizonte, que sean también el contexto emotivo de actividades de la esfera dóxica. 
Aquí habría que precisar que para Husserl pareciera que los sentimientos sensibles implicados en sensaciones y localizados corporalmente o referidos a los sentidos (olores, sonidos) no son el fundamento de lo que llama "resplandor" ni permanecen en el sujeto una vez que ya no está presente el objeto de la suscitación. Lo que permanece es una tonalidad afectiva, meramente representativa, que forma parte del correlato del agrado y que, no obstante, puede perdurar una vez que ya no exhibe afectivamente su objeto. Entonces ya no se habla del acto intencional con su correlato, sino de un temple de ánimo [Stimmung], el cual "preserva la intencionalidad", como el propio Husserl afirma, posteriormente, en un manuscrito de investigación de su proyecto Estudios sobre la estructura de la conciencia ${ }^{30}$.

La cuestión de fondo es que ese tono afectivo de la vivencia, que puede no estar fundido con sensaciones de placer o dolor sensual, es, no obstante, sensible. Decimos con todo derecho no sólo que nos alegra un suceso feliz, sino que sentimos un vivo bienestar más o menos intenso en esa alegría, que no es una sensación localizada pues no nos alegramos en la cabeza o los pies sino, por así decir, en todo lo que somos. ${ }^{31}$ Esto es lo que nos lleva a la cuestión: ¿cabe lla-

El investigador que recibió una buena noticia de su familia vuelve después de recibirla a sus ocupaciones teóricas, pero "se siente contento", siente alegría, y su alegría tiene una referencia intencional a la "buena" noticia que vivió y sigue viviendo con agrado, pero de una forma no temática, ya que su tema son las indagaciones científicas; no obstante, el campo de experiencia de dichas investigaciones, la trama de su pensamiento, incluso tiene un contexto emotivo referido a la noticia que le suscitó agrado.

30 A VI 12 II/72a, "H 20"

${ }^{31}$ Sin embargo, tenemos la aparente paradoja de la relación entre nuestra corporalidad viva y el orden de los sentimientos sensibles en general. En Ideas III, Husserl sugiere que forma parte de la esencia de toda sensación ofrecerse mediata o inmediatamente en la forma de la extensión, asimismo a toda sensación corresponde algún modo de localización corporal. De no ser así, y de acuerdo con la definición de Husserl, no a toda sensación tendría que corresponderle la localización. No obstante, y en concordancia con Ideas II, la localización y la consecuente extensión requerida para que sea localización en un plano extenso es la que constituye en su inmediatez y duración el campo extenso. Sostener lo contrario correría el riesgo de la "espacialización" de la conciencia. La conciencia siente, es decir, intuye sin mediación y la vivencia intuitiva sensible, dura y es ella misma conciencia de sí como duración. El bebé es ya un complejo de sensaciones inmediatas antes de reconocer su propia corporalidad como dotada de extensión realizada. El argumento de Ideas III es el siguiente: "las sensaciones visuales se extienden en un campo, son por principio localizables, bien que en el tipo esencial de la corporalidad que se comprueba en el cuerpo humano está excluida la posibilidad de percepción de una sensación visual localizada o dicho empíricamente, esa posibilidad nos falta a los humanos" (Hua V, 6-7). Según Husserl, como hemos dicho antes, a toda sensación corresponde extensión y por tanto localización. Pero ¿no corresponde a la esencia de la visión la distancia necesaria entre el ver y lo visto? Esta distancia no tiene que ser real-física y, por tanto, en estricta correspondencia con las ubiestesias del tacto, no resulta en una parificación simultánea de las sensaciones del objeto sentido y la corporalidad sentida a su vez en las mismas sensaciones. Los efectos de perspectiva en superficies irregulares, como ocurre en los frescos de la Capilla Sixtina, es un caso claro donde la figura captada no corresponde a la extensión y distribución físico-real de las formas en la superficie percibida. Un poco más adelante, dice Husserl: "el cuerpo humano, sin embargo, es esencialmente una particularización del cuerpo en general y tomado en esa generalidad, es evidente que en la extensión radica la condición fundamental de la posibilidad de la localización y que, por consiguiente, todo género de sensación que se ofrece mediata o inmediatamente en forma de extensión podría ser perceptible de modo localizado" (Hua V, 7). En realidad, es la sensación y no la idea de extensión la que funda la localización y con ella, es la sensación localizada la que funda la 
mar sentimientos sensibles a ambas vivencias no intencionales? incluso, ¿es preciso distinguirlas en absoluto?

Husserl, a juzgar por sus ejemplos, no las separa, y es posible que tenga razón en no hacerlo pues no se trataría de una diferencia entre tipos de vivencias, sino de una diferencia de grado entre vivencias no intencionales del mismo género.

Por un lado, tenemos entonces la sensación sentimental fundida con sensaciones representativas $y$, por otro, una cualidad de sentimiento de la vida que no puede ser localizable al modo del placer y el dolor sensible. Dicha cualidad de sentimiento es independiente de la dirección intencional propia de la vivencia sentimental. Gracias a esta dirección intencional no es pura auto-afección del sujeto en su vivir, sino comparecer del objeto "replandeciendo" en su "amenidad" o "tristeza", aunque este comparecer "cuasi-objetivo" sea sólo para el sujeto de ese sentimiento.

En uno y otro caso tenemos un origen común en la esfera primordial de las síntesis asociativas y la afectividad originaria en donde no se puede distinguir entre sensaciones localizadas que exhiben objetos y los sentimientos sensibles que determinan cualitativamente las vivencias intencionales, con el respectivo resplandor como su correlato, pues nos encontramos en un estadio previo a la intencionalidad. Ya en este nivel, como el propio Husserl declara en sus manuscritos de investigación ${ }^{32}$ : no hay vivencia sin sentimiento; de este modo es posible sugerir un origen común, en la afectividad originaria, de la esfera primordial para ambos sentidos.

Si analizamos el tema en relación con la forma de aprehensión, habrá que decir que la cualidad afectiva determina la forma de la aprehensión; la materia o sentido de aprehensión modificado por la cualidad afectiva es el objeto intencionado por el acto del sentimiento y, finalmente, están los contenidos representantes que manifiestan sensiblemente el objeto de la aprehensión. La cuestión interesante está en que hay que distinguir en los caracteres representantes, los contenidos sensibles que presentan el objeto, y esos mismos contenidos apercibidos como contenidos de sentimiento sensible.

extensión y los puntos localizables en el cuerpo. No es por tanto un contrasentido, como Husserl parece sugerir aquí, hablar de sensaciones inextensas, lo cual no quiere decir que no intervengan en la corporalidad, pero intervienen como constituyentes del cuerpo vivo/extenso [Leibkörper] empíricamente determinado.

${ }_{32}$ Ms. A VI 26, p. 42 a. 
En este contexto, Agustín Serrano ${ }^{33}$ ha señalado que los actos no objetivantes, de acuerdo a Investigaciones Lógicas, no constituyen objetividades, sino que manifiestan determinaciones meramente subjetivas. No obstante, en relación con el pasaje sobre el "suceso feliz" del parágrafo $\$ 15$ de la Quinta Investigación, también advierte que "en él [el suceso feliz] se tematiza el fenómeno sorprendente de que sucesos que uno vive gozosa o sombríamente encierran en su consistencia objetiva una propiedad peculiar cuasi objetiva y que es como un eco del valor propio del suceso. ${ }^{34}$ Lo interesante es que, si bien Husserl no admite para los actos no-objetivantes más objetividad que aquella que es su soporte en un acto objetivante que está implicado en ellos, reconoce este carácter cuasi objetivo.

Este extraordinario fragmento descriptivo llama poderosamente la atención por cuanto el volverse en la alegría hacia el término intencional tiene lugar sobre una representación que además de tener mención intencional y posición objetivante, está vibrando placenteramente, por así decirlo. Y lo hace, al menos en parte, en referencia trascendente: es la calidad, la valía del propio hecho la que "marca el son" del acto y motiva dentro la posterior toma de postura afectiva ${ }^{35}$.

¿Cómo influye la objetividad del valor en la objetividad del resplandor toda vez que el resplandor es por mor del valor que es la base del agrado o desagrado $y$, en esa medida, corresponde al valor en su objetividad, pero sólo se manifiesta para el que vive concretamente el agrado o desagrado? En otras palabras, el resplandor afectivo, visto desde otra óptica, es la manifestación sensible del valor presente en el objeto valioso, en cuya aprehensión originaria como tal están implicadas vivencias afectivas. ¿Cómo conciliar la objetividad de la captación del valor con el carácter individual del resplandor? Por ejemplo, si atendemos la cuestión de la objetivación y consecuente expresión de dichas determinaciones de sentido de la vida afectiva, nos enfrentamos a problemas adicionales derivados de la misma situación: ¿qué decir del gris de la tarde? La tarde no es gris, ni la vemos de color gris, utilizamos esta expresión como una metáfora, es decir, como un rodeo indirecto para expresar una determinación cuasi-objetiva, en este caso, de la tarde como matizada con el color de nuestra tristeza ${ }^{36}$.

\footnotetext{
${ }^{33}$ Agustín Serrano de Haro (1995: 73)

${ }^{34}$ Idem.

${ }^{35}$ Idem.

${ }^{36}$ Hua III/1, p. 292
} 
La referencia representativa matizada de valor se asemeja más a un aura vaga de positividad o negatividad - que a la asunción de una cualidad objetiva de valor; tiene más que ver con el nexo entre las sensaciones y el acto afectivo que con la mención de una calidad axiológica que pudiese fundar en su caso un juicio de valor. Pues de hecho el acto superior de alegría sí permanece como puro modo de referencia, movimiento del ánimo que no comporta en su término intencional una vertiente cualitativa nueva. Bien sea la sola consistencia objetiva del suceso la materia intencional de la alegría, bien sea su "coloración" benévola la que ésta proclame: en ninguno de ambos casos la alegría ocurre en vista de una cualidad peculiar mentada como tal y de la que, más bien, fuese un destello la susodicha coloración subjetiva $^{37}$.

El resplandor afectivo aparece como determinación sensible en la doble dirección de suscitación afectiva sensible, del sujeto afectado por el estado afectivo en cuestión, supongamos la alegría, y simultáneamente, del lado del objeto. Aquello que provoca alegría, aparece teñido por una tonalidad o coloración de lo alegre, resplandece alegría. Para el Husserl de Investigaciones Lógicas, éste era un mero carácter meramente representativo, pero a partir de Ideas, especialmente en Ideas II se comienza a hablar con más detalle del correlato de los actos de sentimiento, ¿tenemos que considerar la suscitación afectiva y el resplandor como contenidos representantes del objeto valioso? Una de las mayores dificultades que impone el paralelismo entre los contenidos representantes intuitivos de la percepción y la función semejante respecto del objeto valioso es la dificultad de generalizar estos datos como momentos necesarios en la aprehensión, puesto que sólo tienen sentido para el sujeto que percibe el objeto valioso, aunque el valor mismo, el valor en cuanto tal, sea objetivo y universal.

Lo cierto es que en la aparición del valor, como veremos en un momento, hay un componente emotivo que reviste el objeto de un determinado resplandor. A pesar de que el resplandor es meramente representativo, y en esa medida, subjetivo, en modo alguno puede decirse sin más que dependa de nuestra voluntad (aunque eventualmente, en ciertos casos, podamos provocar estos efectos), o que el objeto valorado aparezca bajo determinada coloración o tonalidad de resplandor. El resplandor parece pertenecerle al objeto a pesar de que no dependa de ninguna determinación objetiva-real del mismo. Esta pertenencia al objeto, en parte, se debe a que se manifiesta a pesar de nuestra voluntad

\footnotetext{
${ }^{37}$ Agustín Serrano (1995: 74)
} 
$y$, en ese sentido, de la misma forma en que se nos presenta sensiblemente un color o una tonalidad auditiva. Podemos fantasear con que el gato que está frente a nosotros es de color rosado o que brilla en la oscuridad, pero la aparición del gato de color negro y con su negrura como contenido representante en la percepción de ese gato no depende de nuestro gusto y gana. De la misma manera, pareciera que el resplandor afectivo del que habla Husserl se manifiesta como una característica emotiva que pertenece a la representación del objeto, vinculada ciertamente a nuestra valoración y a nuestro estado afectivo, pero de la cual no podemos disponer a voluntad ${ }^{38}$.

\section{EL PROBLEMA DE LA APERCEPCIÓN DEL VALOR Y LOS SENTIMIENTOS SENSIBLES}

EN LOS MANUSCRITOS DE INVESTIGACIÓN DE 1909-1911.

El problema de la apercepción de valor y la coloración afectiva de los sentimientos reaparece en los manuscritos de investigación de entre 1909 y 1911 que más tarde formarán parte de su proyecto inconcluso conocido como Estudios sobre la estructura de la conciencia.

En el mundo de la experiencia concreta comparecen objetos con diferentes niveles de sentido. Cuando digo que algo me agrada, aquello que me agrada aparece ahí ya con los caracteres de su valor, con los rasgos de lo agradable. Lo valioso es asumido así gracias a una cierta representación del objeto de nuestro agrado. Lo que agrada es "algo" agradable y cuya motivación es la apercepción no sólo de los rasgos o caracteres objetivos o, según la nomenclatura de Husserl, "dóxicos", en el objeto, sino que lo agradable del objeto descansa o es motivado por la captación de ciertos caracteres o determinaciones de valor [Wertbestimmtheiten] que se constituyen originariamente en nuestros afectos. ${ }^{39} \mathrm{El}$ objeto individual puede constituirse conforme a sus determinaciones propias, que Husserl Ilama "ousiológicas", es decir, de acuerdo a su "ser" en el

\footnotetext{
38 No hay que olvidar que si bien el resplandor remite a una cierta generalidad en la medida en que podemos identificar el resplandor como resplandor de la alegría o de la tristeza, en cada caso, igual que otros contenidos representantes, se manifiesta de modo concreto y singular. Tomando en cuenta que se trata de modos de concreción intuitiva no objetivos, es decir, que no se pueden contrastar con la comunidad intersubjetiva como sí es posible hacer en percepción normal con los colores o los sonidos, tenemos que la luz o resplandor mantiene una singularidad a la que sólo podemos referirnos expresivamente de modo impropio o, como sugiere Husserl, por rodeos en el $\S 127$ de Ideas I a propósito de la expresión de los nóemas afectivos.

${ }^{39}$ A VI 12 II/84a, "2".
} 
sentido de una "ousía". Fundadas en estos caracteres se encuentran las determinaciones de carácter axiológico relativas a los valores.

La constitución del objeto axiológico referido a las determinaciones axiológicas experimentables del objeto es lo que corresponde a la captación del valor. Para Husserl, así como en la experiencia sensible aparece el objeto natural, así aparece también el valor en la captación del valor. La aparición del valor no se corresponde a la aparición sensible en sentido empírico; no obstante, hay sentimientos sensibles que se corresponden a la exhibición sensible de los objetos, con la consecuente matización de los contenidos de su exhibición perceptiva, como el agrado sensible que acompaña a la exhibición de una textura suave. Pero, advierte Husserl, es necesario distinguir entre estos caracteres fundidos en sensaciones y lo que aquí llama la apercepción del valor.

El valor del objeto "aparece" de manera intuitiva, y quizá a esto se refería en Investigaciones Lógicas con lo que llamaba entonces "el resplandor" que baña o reviste al objeto. Como hemos señalado a propósito de Ideas II, Husserl es de la opinión de que hay una comparecencia intuitiva del valor de las cosas en una captación inmediata semejante a la percepción que llama valicepción [Wertnehmung]. La apercepción del valor es captación del valor en la aparición del objeto, pues los valores, como correlatos de actos fundados se dan originariamente en objetos, es decir, representaciones de actos dóxicos, pero asumidos como "valiosos". El aparecer del valor en el objeto no es una aparición [Erscheinung] en el sentido de la aparición a que dan lugar (por aprehensión) las sensaciones "empíricas", es decir, no se identifica con el mero aparecer sensible de la cosa percibida. Sin embargo, Husserl insistirá aquí en declarar que la aparición de los caracteres de valor es sensible y está vinculada a ciertas formas de incitación de lo que llamará la corriente sensible de sentimiento.

Por otro lado, el rasgo más enigmático de los sentimientos, de acuerdo con la exposición de Husserl en Investigaciones Lógicas, es la irradiación o difusión [Ausbreitung] de ciertos caracteres emotivos, tanto sobre el objeto como al respecto del campo externo de experiencia, la cual Husserl describe como una iluminación, tonalidad emotiva o coloración emotiva. 
El agrado o desagrado, por otra parte, no es la mera toma de posición; de modo que es necesario distinguir entre el agrado y la toma de posición en la captación del valor. La toma de posición es una modificación de la creencia y se enuncia en el juicio ante el valor. Justo aquí es donde cobra su importancia la comparecencia emotiva del objeto con el carácter del resplandor. La mera creencia, dice Husserl, no "colorea" el objeto ${ }^{40}$, la coloración depende de la aparición y por tanto forma parte de la apercepción del objeto. Los predicados de valor, señala Husserl, nacen de la nueva apercepción de la coloración emotiva [Gemütsfärbung] del objeto constituido.

En este contexto llama a las siguientes distinciones: 1) la distinción entre apercepciones sensible-empíricas, "teóricas", y apercepciones "emotivas"; 2) el carácter de intuición del objeto, es decir, intuición incompleta, apercepción vacía no intuitiva; 3) dentro del carácter de intuición la distinción entre intuición simple e intuición emotiva. La primera sería la mera intuición sensible del objeto. Por otro lado, estaría la intuición emotiva, como sensaciones emotivas [Gemütsempfindungen], coloraciones inmanentes de las meras sensaciones [sinnlichen Empfindungen] y finalmente, menciones emotivas [Gemüstdeutungen] ${ }^{41}$.

Por otra parte, en el manuscrito A VI 3042, Husserl expone una consideración importante sobre el tema de la apercepción emotiva del valor. En estas investigaciones, se vuelve de nueva cuenta al problema de la relación entre los sentimientos sensibles y la apercepción empírica. La apercepción emotiva [Gemütsapperzeption], dice Husserl, requiere de una apercepción sensible empírica y, en ella, la objetividad empírica contiene una "coloración" (no empírica), la cual es aprehendida emotivamente.

Las apercepciones emotivas [Gemütsapperzeption] presuponen necesariamente lo empírico sensible, están fundadas en ellos. La objetividad [Gegenständlichkeit] empírica recibe "coloraciones", las cuales son captadas emotivamente (pero no empíri(amente) $)^{43}$.

\footnotetext{
40 A VI 30, 19a.

${ }^{41}$ A VI 30, 220a.

42 Aproximadamente de 1910.

${ }^{43}$ A VI 12 II/29a, "8" "Gemütsapperzeptionen setzen notwendig empirisch sinnliche voraus, sind in innen fundiert. Die empirische Gegenständlichkeit erhält «Färbungen», wird gemütsmässig (aber nicht wieder empirisch) aufgefasst."
} 
En esta cita resulta interesante que Husserl señala que la coloración es aprehendida emotivamente y no empíricamente. En otras palabras, los caracteres aprehendidos emotivamente como "coloración" se aprehenden justo como coloración de ese objeto, pero como contenidos que exhiben ese objeto para mí de forma "meramente representativa" y relativa a mis sentimientos. El problema es que hay sentimientos sensibles fundidos en apercepciones empíricas del objeto, como el dolor y el placer sensible, no obstante, estos sentimientos, que también exhiben determinaciones o cualidades placenteras o no placenteras en el objeto, al estar fundidas en contenidos apercibidos empíricamente, no corresponden al mismo tipo de vivencias que el resplandor.

Finalmente, en el manuscrito A I $16^{44}$ de diciembre de 1911 , Husserl distingue entre el temple alegre y el volverse valorativo hacia el objeto que causa 0 motiva la alegría. Tenemos, por una parte, la apercepción de valor como aprehensión de valor [Wertauffassung] o valicepción [Wertnehmung]. La imagen, señala Husserl, está ahí ya como una imagen bella, o el violín aparece ya lleno de valor, me vuelvo a él con agrado, ya sea porque lo encuentro hermoso, ya porque me parece hermoso el sonido del violín. En cualquier caso, no tengo la mera aprehensión del violín y su sonido, sino todo ello como algo hacia lo cual estoy vuelto en el agrado.

En segundo, lugar tenemos el afecto [Affekt] y la toma de posición emotiva [Gemütsstellungsnahme]. Me siento, menciona Husserl, encantado por el sonido del violín y me vuelvo a él con agrado. O bien, me vuelvo con agrado al objeto mismo, a la madera del violín, a su forma. En ambos casos tenemos, por un lado, el objeto que incita o despierta en el sujeto considerar su carácter de valor [Wertcharackter] y, por otro, presenciamos el agrado con el cual nos volvemos al objeto por su valor.

Las distinciones fenomenológicas corren en el siguiente sentido: 1) el objeto en cuanto tal; 2) los caracteres de valor, positivos o negativos que aparecen con la captación del objeto y 3) la toma de posición emotiva que Husserl llama aquí "afecto" [Affekt], la cual se dirige al objeto en su carácter de valor.

${ }^{44}$ Cfr. Hua XX/2 pp. $484-485$. 
Asimismo, tenemos que, mientras el objeto despierta agrado, a través de su valor, el agrado se dirige al objeto. La toma de posición tiene una dirección, o bien como dirección a favor o en contra, como rechazo. No nos volvemos al objeto en el desagrado, sino que, de acuerdo a lo que Husserl, nos apartamos de él.

El agrado, el alegrarse, puede ser ya calmo, ya apasionado. En agrado podemos distinguir entre el estar vuelto en el agrado y su dirección al objeto, y lo que aquí Husserl llama la corriente de incitación [Strom der Erregung] en el estar vuelto con agrado hacia el objeto. Husserl caracteriza la corriente sensible del agrado de la siguiente manera:

Encontramos entonces una corriente de sentimientos sensibles, corporalmente localizados, que todavía permanecen y normalmente permanece (sí, un tiempo tiene que permanecer), también cuando otra toma de posición se inicie dirigida a otros objetos o una motivación teórica dirigida a otros ${ }^{45}$.

Aquí volvemos, una vez más, sobre el problema de la corriente de sentimientos sensibles localizada corporalmente, la cual, de acuerdo a la descripción que aquí presenta el propio Husserl, correspondería a la suscitación sensible de los temples de ánimo. La "corriente sensible de sentimientos localizados" puede durar, y normalmente dura, dice Husserl, incluso cuando nos encontremos dirigidos en otra toma de posición a otro objeto en consideración teórica.

Un poco más adelante, Husserl señala que el volverse del amor apasionado o el anhelo apasionado, el alegrarse apasionado, no son un volverse en la alegría además de la corriente del sentimiento. Una vez más, me vuelvo con alegría ante el objeto que exhibe caracteres valiosos; al volverme a él con alegría, apasionada o no, hay una suscitación o excitación sensible. La excitación sensible es excitación vinculada al evento mismo de volverse con alegría y es ella la que puede ser más o menos duradera, también es ella la que se manifiesta como una suscitación vivida y localizada en el cuerpo.

\footnotetext{
45 Ms. A I 16/8b, "75", "8" "Wir finden dann einen Strom sinnlicher, körperlich lokalisierter Gefühle, der noch verbleiben kann und normalerweise verbleibt (ja, eine Zeit verbleiben muss), auch wenn eine andere Stellungnahme gerichtet auf andere Objekte oder eine auf andere Objekte gerichtete theoretische Betrachtung einsetzt".
} 
Ahora bien, el volverse con pasión amorosa o el aspirar apasionadamente, el alegrarse apasionadamente, etc., no consisten, empero, en un volverse en el agrado, etc., más una corriente de excitación sensible. En tanto que el arrobo [Entzücken] se dirige al objeto, la aspiración ferviente a lo añorado, etc., la corriente sensible co-pertenece precisamente a lo que se dirige, corriente, empero, que por su lado, como mera corriente sensible, no tiene en absoluto semejante dirección [...] El arrobo y no un agrado sin suscitación, se dirige al objeto, y el objeto no se ve el sol como agradable, sino (en correspondencia con la modificación del acto) como arrebatador $^{46}$.

La descripción del fenómeno coincide con otras descripciones a las que ya hemos hecho referencia. La corriente sensible de sentimiento, como pura corriente sensible, no tiene ninguna dirección; no obstante, ello puede interpretarse de dos formas: 1) se trata nuevamente de presentar los sentimientos sensibles como contenidos no intencionales que ganan su intencionalidad al ser aprehendidos por el acto aprehensor o 2) tienen ellos mismos, los sentimientos, su forma de organización inmanente, que pre-organiza por, así decir, la forma en la que han de ser aprehendidos por los actos. La comparación con la percepción que presenta Husserl aquí puede ser engañosa porque las meras sensaciones no se comportan como los sentimientos sensibles. No corresponde a la exhibición sensible del rojo, como cualidad secundaria de un objeto perceptivo, la misma duración que se mantiene en el sujeto después de que el objeto que causa la alegría deja de estar presente. Esta comparación puede entenderse como una cierta no-independencia de la corriente de sentimiento respecto del "volverse". Así como los contenidos de sensación son no-independientes de la aprehensión cuando se entiende por ellos exhibiciones efectivas de un objeto percibido, así, los contenidos de sentimiento sensible exhiben emotivamente el objeto de la aprehensión emotiva; no obstante, la corriente de sentimiento agrega el carácter adicional de la duración en el sujeto sin el objeto de la suscitación.

\footnotetext{
${ }^{46}$ Idem, "Nun besteht aber die leidenschaftlich-liebende Zuwendung oder das leidenschaftliche Begehren, das leidenschaftliche Sich-Freuen etc. nicht in einer Gefallenszuwendung etc. plus einem Strom sinnlicher Erregung. Indem sich das Entzücken auf das Objekt richtet, das inbrünstige Begehren auf das Vemisste etc., gehört zu dem Sich-Richtenden eben der sinnliche Strom mit, der aber seinerseits als bloß sinnlicher Strom gar keine solche Richtung hat. [...] Das Entzücken, und nicht ein erregungsloses Gefallen, richtet sich auf das Objekt, und das Objekt sieht nicht bloß als gefällig, sondern (der Modifikation des Aktes entsprechend) als entzückend da".
} 
La corriente de sentimientos sensibles tiene una irradiación [Austrahlung] o propagación [Verbreitung] emotiva que no es un mero contorno que rodea al acto, sino que a su modo está conectado con él. La corriente de sentimiento es una con el volverse emotivo y no un solo mero agregado concomitante al volverse. Se trata justamente de la corriente irradiante de sentimiento sensible que motiva ese volverse con alegría al suceso, o incluso al entorno.

Por otra parte, la corriente de sentimiento tiene el correlato noemático de la irradiación de una luz afectiva que descansa sobre el objeto, lo colorea dándole un determinado carácter de sentimiento.

Una luz resplandeciente descansa sobre el objeto, lo colorea, le da carácter. El ser arrebatador es como una corriente de luz que descansa sobre el objeto. En su carácter de luz puede poner la atención; sin embargo ¿no está en ello el objeto como lo que irradia la luz? Está el hecho en belleza irradiante, como en efecto lo decimos realmente de la amada, de una persona hermosa, etc. No es de modo que el arrobo, que yace fuera del objeto en el sujeto, lance una luz al objeto ${ }^{47}$.

El tema de la luz afectiva o resplandor ${ }^{48}$ es, como hemos dicho, un carácter de la representación del objeto. Se trata de un carácter sensible del objeto apartado del estrato de la aprehensión de los contenidos de sensación. Las metáforas visuales con las que Husserl se refiere constantemente a este carácter son justo eso, metáforas, pues esta iluminación no es precisamente una luz, ni está fundada en sentido estricto en las sensaciones que exhiben el objeto. De esto se desprende su independencia y su posible permanencia una vez que ya pasó el objeto que suscitó este estado.

\begin{abstract}
Ahora bien, el carácter de luz no pertenece a la apercepción objetiva, ni a la capa de las aprehensiones de sensación. Pertenece a otra dimensión. Pertenece primigeniamente al objeto, esto es, en el arrobo, que está fundado por la apercepción objetiva, se constituye este carácter primigeniamente como carácter del objeto [Objekt]. (Se podría decir: de igual manera que un sentimiento sensible se construye sobre la conciencia de sensación sensible y es carácter de sentimiento en el objeto,
\end{abstract}

\footnotetext{
${ }^{47}$ Ms. A I 16/10a, "77" "10". "Ein strahlend Licht liegt auf dem Gegenstand, färbt ihn, gibt ihm einen Charakter. Es ist gleichsam das Entzückendsein ein Lichtstrom, der auf dem Objekt liegt. Auf seinen Lichtcharakter kann ich achten. Aber steht dabei nicht das Objekt als das Lichtausstrahlende da? Es steht in der Tat in strahlender Schönheit da, wie wir <es> ja von der Geliebten, von einer schönen Person etc. wirklich sagen. Es ist nicht so, dass das Entzücken, das ausserhalb des Objekts im Subjekt liegt, auf das Objekt ein Licht wirft."

${ }^{48}$ Hay otra apariciones del tema en Hua XXXVIII, 176, Hua XIX/1, 408.
} 
en el contenido de sensación.) No tendríamos que decir: no se trata aquí de una apercepción empírica, de una apercepción tal que le da unidad empírica a un objeto (lo constituye como eso), pero cuando ampliamos la expresión apercepción, se trata de una apercepción. Puedo "vivir" en ella así como en la apercepción empírica, luego estoy vuelto en especial a aquello que en ella se constituye en especial ${ }^{49}$.

La coloración emotiva del objeto es un carácter que depende de una dimensión distinta a la apercepción empírica; no obstante, se comporta de manera semejante a las sensaciones toda vez que exhibe al objeto de acuerdo a caracteres emotivos. La cuestión es que dicha coloración es el resultado de una irradiación o propagación emotiva del volverse en el sentimiento hacia el objeto. El volverse emotivo ${ }^{50}$ hacia el objeto no sólo es provocado por la tonalidad emotiva apercibida en el objeto emotivamente representado sino que, esa misma tonalidad, está esencialmente vinculada con un temple de ánimo que "colorea" afectivamente el fondo de mi situación concreta produciendo lo que Husserl llama un ambiente emotivo [Gefüh/smilieu $]^{51}$.

\section{CONCLUSIONES: LA DIMENSIÓN EMOTIVA DE LA AFECCIÓN}

A lo largo de las consideraciones anteriores, hemos expuesto algunos contextos relativos a la descripción husserliana del lugar de la "tonalidad" o "coloración" emotiva atribuida a la apercepción del valor de los objetos de la experiencia. La coloración en tanto vivencia aperceptiva, tendría que guardar alguna relación con la sensibilidad aunque en cierto modo, la tiene. No asociamos en vano el significado común de "sentir" (Fühlen) tanto para la mera sensibilidad como para formas de afectividad no localizadas corporalmente, la esfera entera de los sentimientos. Sin embargo, existe una diferencia fenomenológicamente

\footnotetext{
49 Ms. A I $16 / 10$ b. "Nun gehört der Lichtcharakter nicht zur Gegenstandsapperzeption, nicht zur Schicht der Empfindungsauffassungen. Es gehört in eine andere Dimension. Er gehört ursprünglich zum Objekt d.i. im Entzücken, das fundiert ist durch die Gegenstandsapperzeption, konstituiert sich dieser Charakter ursprünglich als Charakter des Objekts. (Ich könnte sagen: Ebenso wie ein sinnliches Gefühl auf einem sinnlichen Empfindungsbewusstsein sich baut und Gefühlscharakter am Gegenstand, am Empfindungsinhalt ist.) Müssen wir also nicht sagen: Es handelt sich hier nicht um eine empirische Apperzeption, um eine solche, die einem Gegenstand empirische Einheit gibt (ihn als das konstituiert), aber wenn wir den Ausdruck Apperzeption erweitern, eben auch um eine Apperzeption. Ich kann in ihr wie <in> der empirischen Apperzeption "leben", dann bin ich dem, was sich in ihr speziell konstituiert, speziell zugewendet." ${ }^{50} \mathrm{Cfr}$. Ms. A VI 12/II, 95a

${ }^{51}$ Años después, en un manuscrito de los años veinte, que forma parte de sus lecciones de Ética, encontramos una nueva referencia al tema de la apercepción del valor y la resonancia corporal con el ambiente emotivo que refuerza el rol de la vida corporal en la apercepción de la coloración afectiva involucrada en la experiencia de valor. Hua XXXVII, 343.
} 
relevante y difícil de describir entre la apercepción emotiva del valor: la suscitación de la experiencia de la "coloración emotiva" que resulta de su apercepción, y la aprehensión del valor en cuanto tal. Los contenidos de aprehensión que ofrece la apercepción emotiva del valor no tienen el mismo comportamiento que aquellos contenidos de la apercepción empírica que son aprehendidos como exhibición sensible del objeto de la percepción.

Si bien resulta difícil no involucrar a la vivencia del cuerpo en nuestra experiencia afectiva en general, también es claro que existe cierta forma de afectividad del sentimiento que carece de localización corporal precisa y, sin embargo, también funciona como momentos de aprehensión de actos intencionales de sentimiento, o vivencias cuya intencionalidad no está definida, como los temples de ánimo.

Dado que es la corporalidad viva como centro cero de orientación la que funda el espacio, por así decir, extenso, funda con él la dimensión extensional que le da sentido a la localización como localización en un cuerpo [Leibkörper] ya constituido en el espacio físico, y lo propio de las sensaciones no es en principio la localización sino su carácter temporal. Existe una anterioridad lógica que permite hablar sin contradicción de la afectividad sensible en general como referida siempre a la corporalidad viva [Leiblickheit] sin que ello nos comprometa a una localización específica en el cuerpo ya constituido como [Leibkörper].

Por lo anterior, podemos distinguir entre sentimientos de sensación entrelazados directamente con sensaciones localizadas y sensaciones que, sin dejar de ser sensaciones de la conciencia en su cuerpo vivo, no requieren en principio una localización precisa. Así, el conjunto de sensaciones localizadas concomitantes (opresión en el pecho, sensación de vacío en el estómago) son en cierto modo la manifestación corporal localizada de esos sentimientos sensibles, pero el vínculo causal que los asocia corresponde a un orden de explicación que no es fenomenológico, toda vez que remiten a la conformación fisiológica de ciertos sujetos fácticos humanas afectados con sensaciones localizadas de acuerdo a su constitución física fáctica.

Desde el punto de vista fenomenológico-reflexivo lo único que se puede hacer es declarar o señalar la ocasión de su presencia, mas no hay necesidad esencial de la relación entre la opresión en el pecho y el sentimiento de tristeza. Sin embargo, la tristeza se siente, y se siente en el cuerpo. Las metáforas 
corporales de pesadez, opresión y oscurecimiento tienen su fundamento en la forma en la que sentimos nuestro cuerpo vivo en el estado de ánimo de la tristeza. Cuando Husserl se refiere a la corriente de sentimiento sensible duradera, que es el modo de manifestación noética del temple de ánimo o "Stimmung", lo hace en alusión al cuerpo. ${ }^{52} \mathrm{Si}$ agregamos que a esto corresponde un correlato noemático de la corriente de sentimientos sensibles de un estado de ánimo, tal como "la tonalidad afectiva del entorno" como "iluminación", hay buenas razones para pensar que la concreción del ahí de la "iluminación" forma parte del horizonte cinestésico que abre el cuerpo vivo. El mundo es un entorno concreto relativo a mí como realidad incorporada en dicho mundo que, no obstante, yo mismo constituyo, a la vez que es "coloreado" o "iluminado", en cierto modo, por mi temple de ánimo.

Los sentimientos sensibles, cuya resonancia se vive corporalmente, no están fundidos con ninguna apercepción empírica y, por lo tanto, no corresponden ni a una localización corporal específica ni a la apercepción empírica de cualidades primarias o secundarias en los objetos. La belleza manifiesta en el objeto, que motiva el interés y es el fundamento del volverse con agrado a él, tiene su fundamento en una apercepción emotiva, pero es irreductible a la apercepción empírica del objeto. De la misma forma el regocijo que nos provoca su belleza, lo vivimos ya como un agrado también corporal cuyo sentido asociamos al "briIlo" de la belleza del objeto, sin que ello resulte en una localización corporal específica. El agrado ante la belleza, además, despliega cierta tonalidad "de lo agradable" que permea la atmósfera entera de la situación. Husserl, como hemos visto a lo largo trabajo, utiliza a menudo la metáfora de la luz para referirse a esta tonalidad. Es la misma luz la que nos entrega el espectro visible de las cosas que no son la luz, con los colores que atribuimos como propiedades de las cosas, pero, por efecto del tipo de luz y la forma concreta en la cual ella los ilumina, esas cosas comparecen matizadas por ese color, como si se tratara de un filtro. Así, nuestro temple de ánimo acrisola el espectro de la percepción y nos entrega, a través de una tonalidad siempre captada sensible y emotivamente, las mismas cosas que compartimos con los demás aunque "iluminadas" por la significatividad que les brinda su valor para nosotros.

52 Hua XXXVII, p.327 


\section{BIBLIOGRAFÍA}

BeRnet, R., (2006): "Zur Phänomenologie von Trieb und Lust bei Husserl" in Lohmar D./Fonfara (Hg.), Interdisziplinäre Perspektiven der Phänomenologie. Neue Felder der Kooperation: Cognitive Science, Neurowissenschaft, Dordrecht/Boston/London,38-53

FerRer SANTOS, Urbano, (2012): "Razón axiológica y práctica en Husserl", Veritas, No. 27, Septiembre, pp. 77-95.

HUSSERL, Edmund, (1950-2014): Gesammelte Werke, Dortrecht/Boston/London, Springer, Vols. III/1, IV, V, XIX/1, XX/2, XXVIII, XXXVII y Manuscritos inéditos: Ms. A VI 30; A I 16; A VI 12/II; A VI 26, A VI 30.

Iribarne, V. Julia, (2013): "El sentimiento como condición de posibilidad de la ética (E. Husserl). Acerca del sentimiento según diferentes perspectivas". Anuario Colombiano de Fenomenología, pp. 105-118.

LiANGKANG, Ni, (2007): "The Problem of the phenomenology of Feeling in Husserl and Scheler" en K-Y.Lau and J.L Drummond (eds.) Husserl's Lógical Investigations in the New Century: Western and Chinese Perspectivas, Netherlands: Springer,.

Melle, Ulrich, (1991): "The Development of Husserl's Ethics", Études Phénomenologiques, No. 13-14.

- (2012): "Husserls descriptive Erforschung der Gefühlserlebnisse", en R. Breeur and U.Melle, (Ed.) Life, Subjectivity and Art: Essays in Honor of Rudolf Bernet, Phaenomenologica 201, Springer, p.51-99.

QUePons, I. (2015): "Intentionality of Moods and Horizon Consciousness in Husserl's Phenomenology", in Martha Ubiali and Mareen Wehrle, Feeling and value, willing and action, Phaenomenologica, 216, Springer.

Schumman, K. (1977): Husserl-Cronik, Denk- und Lebensweg Edmund Husserls, Husserliana Dokumente 1, La Haya: Martinus Nijhoff.

SerRano de Haro, Agustín (1995): "Actos básicos y actos fundados. Exposición crítica de los primeros análisis husserlianos", Anuario Filosófico, Universidad de Navarra, Número 28.

VongeHR, Thomas, (2004): "Husserl über Gemüt und Gefühl in den Studien zur Struktur des Bewusstseins", en Beatrice Centi e Gianna Gigliotti Fenomenologia della Ragion Pratica, L'Etica di Edmund Husserl, Bibliopolis, Napoli, pp.227-253.

- (2011): "Husserls Studien über Gemüt und Wille" en Verena Mayer, Christopher Erhard and Marisa Scherini (eds.) Die Aktualität Husserls, Freiburg im Breisgau: Alber, 335360.

Zirión, Antonio (2009): "El resplandor de la afectividad", en Acta Fenomenológica Latinoamericana, Volumen III (Actas del IV Coloquio Latinoamericano de Fenomenología) Lima/Morelia: Círculo Latinoamericano de Fenomenología, Pontificia Universidad Católica de Perú, Universidad Michoacana de San Nicolás de Hidalgo. 